\title{
O MODELO DE PRECIFICAÇÃO DE ATIVOS DE CAPITAL: TEORIA E EVIDÊNCIAS
}

\section{RESUMO}

Distante quatro décadas de seu aparecimento, o modelo de precificação de ativos de capital proposto pelo Nobel William Sharpe e por John Lintner, conhecido como CAPM, é ainda o modelo mais amplamente utilizado na estimativa do custo de capital de empresas e na avaliação de carteiras. $\mathrm{O}$ fato se deve às poderosas previsões permitidas pelo modelo sobre a medida do risco e a relação entre risco e retorno. $\mathrm{O}$ objetivo deste artigo é mostrar que o CAPM apresenta algumas falhas empíricas associadas a simplificações teóricas e dificuldades de implementação de testes que sejam válidos para o modelo. A conclusão do artigo é que as limitações do CAPM representam desafios a serem explicados por modelos alternativos.

\section{Eugene F. Fama \\ Universidade de Chicago}

\section{Kenneth R. French}

Universidade de Dartmouth

\begin{abstract}
Four decades after its advent, the capital assets pricing model proposed by Nobel Prize laureate William Sharpe and by John Lintner, known as CAPM, remains the most widely used model in estimating firms' cost of capital and valuing portfolios. This is due to the model's predictive power for risk and risk-return ratios. The purpose of this article is to show that CAPM has empirical flaws associated with theoretical simplifications and difficulties implementing valid tests for the model. The article concludes that the limitations of CAPM are challenges to be explained by alternative models.
\end{abstract}

PALAVRAS-CHAVE Modelo de precificação de ativos, custo de capital, avaliação de carteiras, risco e retorno esperado, teste empírico.

KEYWORDS Asset pricing model, cost of capital, risk and expected return, portfolio evaluation, empirical test. 


\section{INTRODUÇÃO}

O modelo de precificação de ativos de capital (CAPM) de William Sharpe (1964) e John Lintner (1965) marca o nascimento da teoria da precificação de ativos (tendo resultado no agraciamento de Sharpe com o Prêmio Nobel, em 1990). Quatro décadas após, o CAPM ainda é largamente utilizado em aplicações como a estimativa do custo do capital das empresas e a avaliação de carteiras. É o elemento central dos MBAs em investimentos. Na verdade, muitas vezes é o único modelo de precificação de ativos ensinado nesses cursos. ${ }^{1}$

O apelo do CAPM está no fato de que oferece previsões poderosas e intuitivamente agradáveis sobre a medida do risco e a relação entre retorno e risco. Infelizmente, o histórico empírico do modelo é fraco - fraco o bastante para invalidar a maneira como é empregado. Os problemas empíricos do CAPM podem refletir falhas teóricas resultantes de um grande número de premissas simplificadoras. Mas também podem ser causados por dificuldades na implementação de testes válidos para o modelo. Por exemplo, o CAPM afirma que o risco de uma ação deve ser medido em relação a uma "carteira de mercado" abrangente, que, em tese, deveria incluir não só ativos financeiros negociados, mas também bens de consumo duráveis, imóveis e capital humano. Mesmo que adotemos uma visão restritiva do modelo e limitemos sua aplicação a ativos financeiros negociados, seria legítimo restringir ainda mais a carteira de mercado a ações ordinárias dos Estados Unidos (uma escolha comum)? Ou deve-se ampliar o mercado de maneira a incluir debêntures e outros ativos financeiros, quiçá do mundo todo? No fim das contas, argumentamos que, se os problemas do modelo refletem fraquezas da teoria ou da implementação, o fracasso do CAPM em ensaios empíricos implica a invalidez da maioria das aplicações do modelo.

Começaremos por delinear a lógica do CAPM concentrando-nos em suas previsões sobre risco e retorno esperado. Então reveremos o histórico dos trabalhos empíricos e o que nos dizem a respeito das limitações do CAPM, que representam desafios a serem explicados por modelos alternativos.

\section{A lógica do CAPM}

O CAPM parte do modelo de escolha da carteira desenvolvido por Harry Markowitz (1959). No modelo de Markowitz, um investidor escolhe uma carteira em um momento $t-1$ que produza um retorno estocástico em t. O modelo admite que os investidores sejam avessos ao risco e que, ao escolherem entre carteiras, preocupem- se apenas com a média e a variância do retorno de seu investimento de um período. Com isso, os investidores escolhem carteiras "eficientes em média-variância" desde que as carteiras 1) minimizem a variância do retorno da carteira dado o retorno esperado e 2) maximizem o retorno esperado dado a variância. Assim, a abordagem de Markowitz é freqüentemente chamada de "modelo de média-variância."

O modelo de carteira fornece uma condição algébrica dos pesos dos ativos em carteiras eficientes em média-variância. O modelo transforma essa declaração algébrica em uma previsão testável da relação entre risco e retorno esperado, identificando uma carteira que deve ser eficiente para que os preços dos ativos "fechem" em todos os mercados.

Sharpe (1964) e Lintner (1965) acrescentam duas premissas ao modelo de Markowitz para identificar uma carteira que deva ser eficiente em média-variância. A primeira premissa é plena concordância: dados os preços dos ativos a que o mercado fecha em $t-1$, os investidores concordam a respeito da distribuição conjunta dos rendimentos dos ativos de $t-1$ a $t$. E essa é a distribuição verdadeira - ou seja, aquela de onde retiramos os retornos que usamos para testar o modelo. A segunda premissa é a de que há tomada e concessão de empréstimos à taxa livre de risco, que é a mesma para todos os investidores e independe do montante tomado ou concedido.

A Figura 1 descreve as oportunidades de carteira e conta a estória do CAPM. O eixo horizontal mostra o risco da carteira medido pelo desvio padrão do retorno da carteira; o eixo vertical mostra o retorno esperado. A curva $a b c$, a que chamamos de fronteira de variância mínima, traça combinações de retorno esperado e risco de carteiras de ativos arriscados que minimizam a variância do retorno a diferentes níveis de retorno esperado (essas carteiras não incluem tomada e concessão de empréstimos livres de risco). O tradeoff entre risco e retorno esperado por carteiras de variância mínima é evidente. Por exemplo, um investidor que deseje um elevado retorno esperado, no nível do ponto $a$, digamos, precisará aceitar elevada volatilidade. No ponto $T$, o investidor pode obter um retorno esperado intermediário com menor volatilidade. Se não houver tomada ou concessão de empréstimos à taxa livre de risco, apenas as carteiras acima de $b$ e ao longo de $a b c$ serão eficientes em média-variância, uma vez que elas também maximizam o retorno esperado, dadas as variâncias de seu retorno.

O acréscimo de tomada e concessão à taxa livre de risco transforma o conjunto eficiente em uma reta. Imaginemos uma carteira que invista a proporção $x$ de seus recursos em um título livre de risco e 1 - $x$ em uma carteira $g$. Se 
todos os recursos forem investidos no título livre de risco - ou seja, dados em empréstimo à taxa de juros livre de risco -, o resultado será o ponto $R f$ da Figura 1, uma carteira de variância zero e taxa de retorno livre de risco. Combinações de concessão de empréstimos à taxa livre de risco e de investimento positivo no ponto $g$ da linha reta que vai de $R f$ a $g$. Os pontos à direita de $g$ na linha representam tomada de empréstimo à taxa livre de risco, sendo os proventos da tomada de empréstimo usados para aumentar o investimento da carteira $g$. Em suma, carteiras que combinem concessão ou tomada à taxa livre de risco com uma carteira arriscada $g$ são representadas por uma linha reta que sai de $R f$ e passa por $g$ na Figura $1 .^{2}$

Para obtermos as carteiras eficientes em média-variância disponíveis com tomada e concessão de empréstimos à taxa livre de risco, traçamos uma linha de $R f$ na Figura 1 para cima e para a esquerda até a carteira tangente $T$. Podemos ver, assim, que todas as carteiras eficientes são combinações do ativo livre de risco (seja tomada ou concessão de empréstimo à taxa livre de risco) com uma só carteira tangente arriscada, $T$. Esse resultado crucial é o "teorema da separação" de Tobin (1958).

A moral da estória do CAPM fica, agora, evidente. Com plena concordância a respeito da distribuição dos retornos, todos os investidores enxergam o mesmo conjunto de oportunidades (Figura 1) e combinam a mesma carteira tangente $T$ com tomada ou concessão de empréstimos à taxa livre de risco. Como todos os investidores detêm a mesma $T$ de ativos arriscados, ela deve ser a carteira de ativos de risco ponderada pelo valor. Mais especificamente, o peso de cada ativo de risco na carteira tangente, que passamos a chamar de $M$ (de "mercado"), deve ser o valor total de mercado de todas as unidades circulantes do ativo dividido pelo valor total de mercado de todos os ativos de risco. Além disso, a taxa livre de risco deve ser fixada (juntamente com os preços dos ativos de risco) de maneira a fechar o mercado de tomada e concessão de empréstimos à taxa livre de risco.

Em suma, as premissas do CAPM implicam que a carteira de mercado $M$ deva estar sobre a fronteira de variância mínima para que o mercado de ativos feche. Isso quer dizer que a relação algébrica que se aplica a qualquer carteira de variância mínima deve, também, aplicar-se à carteira de mercado. Especificamente, se houver $\mathrm{N}$ ativos de risco,

(Condição de Variância Mínima para $M$ )

$$
E\left(R_{i}\right)=E\left(R_{z M}\right)+\left[E\left(R_{M}\right)-E\left(R_{z M}\right)\right] \beta_{i M}, i=1, \ldots, N
$$

Nesta equação, $E\left(R_{i}\right)$ é o retorno esperado do ativo $i$ e $\beta_{i \mathrm{M}}$, o beta de mercado do ativo $i$, é a covariância de seu retorno e do retorno do mercado dividida pela variância do retorno do mercado,

(Beta do Mercado) $\quad \beta_{i M}=\frac{\operatorname{cov}\left(R_{i}, R_{M}\right)}{\sigma^{2}\left(R_{M}\right)}$

Figura 1 - Oportunidades de Investimento.

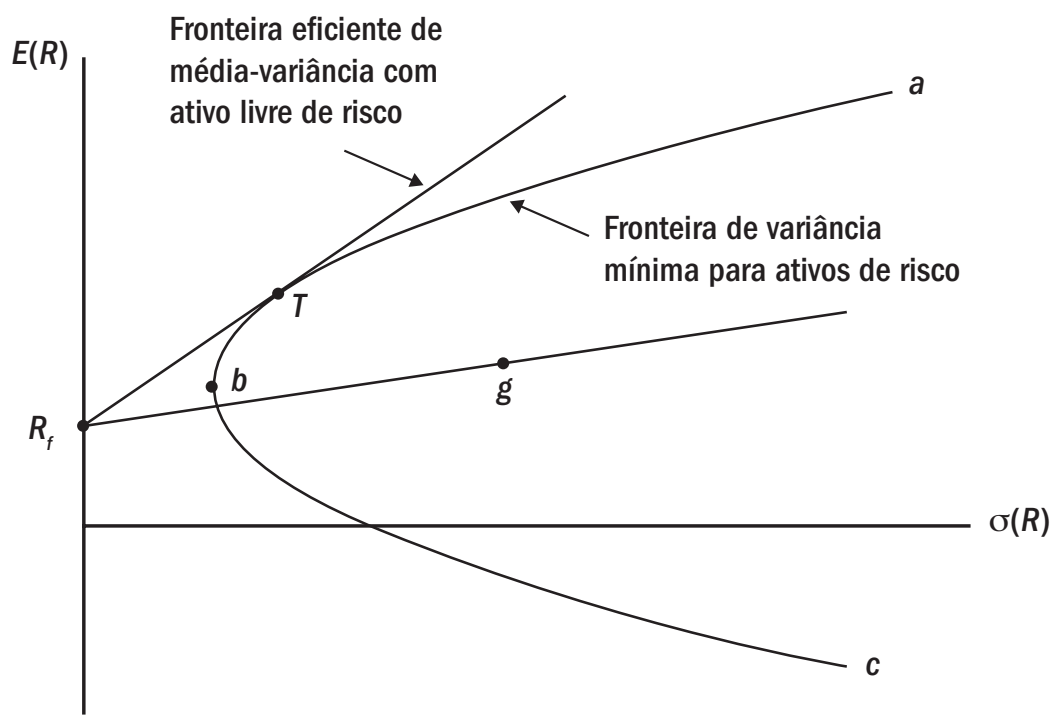


O primeiro termo do lado direito da condição de variância mínima, $E\left(R_{z M}\right)$, é o retorno esperado de ativos com betas de mercado iguais a zero, o que quer dizer que seus retornos não estão correlacionados com o retorno do mercado. O segundo termo é um prêmio pelo risco o beta de mercado do ativo $i, \beta_{i M}$, vezes o prêmio por unidade de beta, que é o retorno esperado do mercado, $E\left(R_{M}\right)$, menos $E\left\{R_{z M}\right)$.

Como o beta de mercado do ativo $i$ é, também, a inclinação da regressão de seu retorno sobre o retorno do mercado, uma interpretação comum (e correta) do beta é que ele mede a sensibilidade do retorno do ativo à variação do retorno do mercado. Mas há outra interpretação do beta que condiz melhor com o espírito do modelo de carteira subjacente ao CAPM. O risco da carteira de mercado medido pela variância de seu retorno (o denominador de $\beta_{i M}$ ) é uma média ponderada dos riscos de covariância dos ativos em $M$ (os numeradores de $\beta_{i \mathrm{M}}$ para diferentes ativos). Assim, $\beta_{i M}$ é o risco de covariância do ativo $i \mathrm{em}$ $M$ medido em relação ao risco médio de covariância dos ativos, que é simplesmente a variância do retorno do mercado. ${ }^{3}$ Em termos econômicos, $\beta_{i M}$ é proporcional ao risco com que cada dólar investido no ativo $i$ contribui para a carteira de mercado.

O último passo no desenvolvimento do modelo SharpeLintner é usar a premissa de tomada e concessão de empréstimos à taxa livre de risco para identificar $E\left(R_{z M}\right), o$ retorno esperado de ativos de beta zero. O retorno de um ativo de risco não apresenta correlação com o retorno do mercado - tem beta igual a zero - quando a média das covariâncias do ativo em relação aos retornos dos demais ativos apenas compensa a variância do retorno do ativo. Tal ativo de risco é livre de risco na carteira de mercado, no sentido de que nada contribui para a variância do retorno do mercado.

Quando há tomada e concessão de empréstimos à taxa livre de risco, o retorno esperado dos ativos que não estão correlacionados com o retorno do mercado, $E\left(R_{z M}\right)$, deve ser igual à taxa livre de risco, $R_{f}$ A relação entre retorno esperado e beta passa a ser, então, a familiar equação do CAPM de Sharpe-Lintner,

(CAPM de Sharpe-Lintner)

$$
E\left(R_{i}\right)=R_{f}+\left[E\left(R_{M}\right)-E\left(R_{i}\right)\right] \beta_{i M}, i=1, \ldots, N
$$

Verbalmente, o retorno esperado de qualquer ativo $i$ é a taxa de juros livre de risco, $R_{f}$, mais um prêmio pelo risco, que é o beta de mercado do ativo, $\beta_{i \mathrm{M}}$, vezes o prêmio por unidade de risco beta, $E\left(R_{M}\right)-R_{f}$
A tomada e concessão irrestrita de empréstimos à taxa livre de risco é uma premissa irreal. Fischer Black (1972) desenvolveu uma versão do CAPM sem tomada ou concessão de empréstimos à taxa livre de risco. Ele demonstrou que o resultado central do CAPM - ser a carteira de mercado eficiente em média-variância - pode ser alternativamente obtido permitindo vendas short irrestritas dos ativos de risco. Resumindo, de volta à Figura 1, se não houver ativo livre de risco, os investidores escolhem carteiras ao longo da fronteira eficiente em média-variância de $a$ a $b$. Os preços que fecham o mercado implicam que, quando se ponderam as carteiras escolhidas pelos investidores por suas participações (positiva) na riqueza investida agregada, a carteira resultante é a carteira de mercado. A carteira de mercado é, portanto, uma carteira das carteiras eficientes escolhidas pelos investidores. Com venda short irrestrita dos ativos de risco, as carteiras compostas de carteiras eficientes são, elas mesmas, eficientes. Assim, a carteira de mercado é eficiente, o que significa que a condição de variância mínima para $M$ dada acima se sustenta e é a relação entre retorno esperado e risco do CAPM de Black.

As relações entre o retorno esperado e o beta de mercado das versões de Black e Sharpe-Lintner do CAPM diferem apenas em termos do que cada uma diz sobre $E\left(R_{z M}\right)$, o retorno esperado de ativos não correlacionados com o mercado. A versão de Black diz apenas que $E\left(R_{z M}\right)$ deve ser menor que o retorno esperado do mercado, de tal modo que o prêmio pelo beta seja positivo. Por outro lado, na versão Sharpe-Lintner do modelo, $E\left(R_{z M}\right)$ deve ser a taxa de juros livre de risco, $R f$, e o prêmio por unidade de risco beta é $E\left(R_{M}\right)-R_{f}$.

A premissa de vendas short irrestritas é tão irreal quanto a de tomada e concessão de empréstimos à taxa livre de risco. Se não houver ativo livre de risco e não for permitida a venda short dos ativos de risco, os investidores em média-variância ainda optarão por carteiras eficientes - os pontos acima de $b$ na curva $a b c$ da Figura 1. Mas quando não há venda short dos ativos de risco nem ativos livres de risco, a álgebra da eficiência da carteira nos diz que carteiras compostas de carteiras eficientes não serão tipicamente eficientes. Isso significa que a carteira de mercado, que é uma carteira das carteiras eficientes escolhidas por investidores, não é tipicamente eficiente. E a relação CAPM entre retorno esperado e beta de mercado se perde. Isso não elimina as previsões de retorno esperado e betas no que tange a outras carteiras eficientes - se a teoria for capaz de especificar carteiras que devam ser eficientes para que o mercado feche. Mas, por enquanto, isso não se revelou possível. 
Em suma, a familiar equação do CAPM que relaciona os retornos esperados do ativo a seus betas de mercado é apenas uma aplicação à carteira de mercado da relação entre retorno esperado e beta da carteira que se sustenta em qualquer carteira eficiente em média-variância. A eficiência da carteira de mercado se baseia em muitas premissas irreais, inclusive concordância plena e tomada e concessão irrestrita de empréstimos à taxa livre de risco ou venda short irrestrita de ativos de risco. Mas todos os modelos interessantes envolvem simplificações irreais, e é por isso que devem ser testados em relação a dados concretos.

\section{Primeiros testes empíricos}

Os testes do CAPM se baseiam em três implicações da relação entre retorno esperado e beta de mercado implícitas no modelo. Primeiro, os retornos esperados de todos os ativos apresentam relação linear com seus betas e nenhuma outra variável tem poder explicativo marginal. Segundo, o prêmio do beta é positivo, o que significa que o retorno esperado da carteira de mercado supera o de ativos cujos retornos não estejam correlacionados com o retorno do mercado. Terceiro, na versão SharpeLintner do modelo, os ativos não correlacionados com o mercado têm retornos esperados iguais à taxa de juros livre de risco, e o prêmio do beta é o retorno esperado do mercado menos a taxa livre de risco. A maioria dos testes dessas previsões usa regressões longitudinais ou de série temporal. As duas abordagens datam dos primeiros testes do modelo.

\section{Testes do Prêmio pelo Risco}

Os primeiros testes de regressão longitudinal se concentram nas previsões do modelo Sharpe-Lintner sobre o intercepto e a inclinação da relação entre retorno esperado e beta de mercado. A abordagem envolve regredir um corte longitudinal dos rendimentos médios dos ativos em relação a estimativas dos betas dos ativos. O modelo prevê que o intercepto dessas regressões seja a taxa de juros livre de risco, $R f$, e que o coeficiente de beta seja o retorno esperado do mercado além da taxa livre de risco, $E\left(R_{M}\right)-R_{f}$

Logo ficaram evidentes dois problemas desses testes. Primeiro, as estimativas dos betas de ativos individuais são imprecisas, o que cria um erro de mensuração quando são usadas para explicar retornos médios. Segundo, os resíduos das regressões têm fontes comuns de variação, como efeitos setoriais sobre os retornos médios. Uma correlação positiva entre os resíduos produz uma distorção para menos nas estimativas normais pelo mínimo quadrado do erro padrão das inclinações da regressão longitudinal.

Para aumentar a precisão dos betas estimados, pesquisadores como Blume (1970), Friend e Blume (1970) e Black, Jensen e Scholes (1972) trabalham com carteiras, não com títulos individuais. Como os retornos esperados e os betas de mercado se combinam da mesma maneira em carteiras, se o CAPM explicar os rendimentos dos títulos, também explicará o retorno das carteiras. ${ }^{4}$ As estimativas do beta de carteiras diversificadas são mais precisas do que as de títulos individuais. Assim, usar carteiras em regressões longitudinais dos retornos médios dos betas reduz os erros críticos do problema das variáveis. Mas o agrupamento reduz a amplitude dos betas e o poder estatístico. Para atenuar esse problema, os pesquisadores classificam os títulos por beta na formação de carteiras; a primeira carteira contém os títulos de menor beta e assim por diante, até chegar à última carteira, com os ativos de mais alto beta. Esse procedimento de classificação é hoje padrão em testes empíricos.

Fama e MacBeth (1973) propõem um método para lidar com o problema de inferência causado pela correlação entre os resíduos em regressões longitudinais. Em vez de estimar uma só regressão longitudinal de rendimentos mensais médios dos betas, estimam regressões mês a mês dos rendimentos mensais dos betas. As médias em série temporal das inclinações e dos interceptos mensais, juntamente com os erros padrão das médias, são então usados para verificar se o prêmio médio do beta é positivo e se o retorno médio dos ativos não correlacionados com o mercado é igual à taxa de juros livre de risco média. Nessa abordagem, os erros padrão do intercepto e da inclinação médios são determinados pela variação mês a mês dos coeficientes de regressão, o que capta plenamente os efeitos da correlação entre os resíduos sobre a variação dos coeficientes de regressão, mas deixa de lado a questão de estimar efetivamente as correlações. As correlações dos resíduos são, com efeito, captadas por meio de amostragem reiterada dos coeficientes de regressão. Essa abordagem também se tornou padrão na literatura.

Jensen (1968) foi o primeiro a observar que a versão Sharpe-Lintner da relação entre retorno esperado e beta de mercado também implica um teste de regressão de série temporal. O CAPM de Sharpe-Lintner afirma que o valor esperado do retorno excedente de um ativo (o retorno do ativo menos a taxa de juros livre de risco, Rit - Rft) é completamente explicado por seu prêmio pelo risco esperado do CAPM (seu beta multiplicado pelo valor esperado de $R M t$ - Rft). Isso significa que o "alfa de Jensen", o termo de intercepto na regressão de série temporal, 
(Regressão de Série Temporal)

$$
R_{i t}-R_{f t}=\alpha_{i}+\beta_{i M}\left(R_{M t}-R_{f t}\right)+\varepsilon_{i t}
$$

é de zero para cada ativo.

Os primeiros testes rejeitam veementemente a versão Sharpe-Lintner do CAPM. Existe uma relação positiva entre beta e retorno médio, mas é excessivamente horizontal. É preciso lembrar que, em regressões longitudinais, o modelo Sharpe-Lintner prevê que o intercepto seja a taxa livre de risco e o coeficiente de beta seja o retorno esperado do mercado além da taxa livre de risco, $E\left(R_{M}\right)-R_{f}$ As regressões concluem, consistentemente, que o intercepto é maior do que a taxa livre de risco média (normalmente representada pelo rendimento de um T-bill de um mês) e o coeficiente de beta é menor do que o retorno excedente médio do mercado (representado como o retorno médio de uma carteira de ações ordinárias americanas menos a taxa do T-bill). Isso é verdadeiro nos primeiros testes, como os de Douglas (1968), Black, Jensen e Scholes (1972), Miller e Scholes (1972), Blume e Friend (1973) e Fama e MacBeth (1973), e em testes mais recentes de regressão longitudinal, como os de Fama e French (1992).

A evidência de que a relação entre beta e retorno médio é horizontal demais se confirma em testes em séries temporais, como os de Friend e Blume (1970), Black, Jensen e Scholes (1972) e Stambaugh (1982). Os interceptos das regressões de série temporal dos rendimentos excedentes de ativos em relação ao retorno excedente do mercado são positivos para ativos de baixo beta e negativos para os de beta elevado.

A Figura 2 fornece um exemplo atualizado das evidências. Em dezembro de cada ano, estimamos um beta pré-ranking de cada ação da NYSE [Bolsa de Valores de Nova York] (1928-2003), da AMEX (1963-2003) e da NASDAQ (1972-2003) presente na base de dados do CRSP (Centro de Pesquisa de Preços de Títulos da Universidade de (hicago), usando de dois a cinco anos, dependendo da disponibilidade de rendimentos mensais anteriores. ${ }^{5}$ Em seguida, formamos dez carteiras ponderadas pelo valor com base nesses betas pré-ranking e calculamos seus retornos para os próximos 12 meses. Repetimos o processo para cada ano de 1928 a 2003. O resultado é de 912 retornos mensais de dez carteiras classificadas por beta. A Figura 2 traça o retorno médio de cada carteira em relação ao beta pós-ranking, estimado pela regressão dos rendimentos mensais de 1928-2003 em relação ao rendimento da carteira de ações ordinárias americanas ponderadas pelo valor do CRSP.

O CAPM de Sharpe-Lintner prevê que as carteiras se situem ao longo de uma linha reta de intercepto igual à taxa livre de risco, $R f$, e inclinação igual ao rendimento excedente esperado do mercado, $E\{R M)$ - Rf. Para estimar a linha prevista na Figura 2, usamos a taxa média do T-bill de um mês e o retorno excedente médio do mercado do CRSP entre 1928-2003. Confirmando evidências anterio-

Figura 2 - Retornos Mensais Médios Anualizados e Beta de Carteiras Ponderadas pelo Valor Formadas com Base no Beta Anterior, 1928-2003.

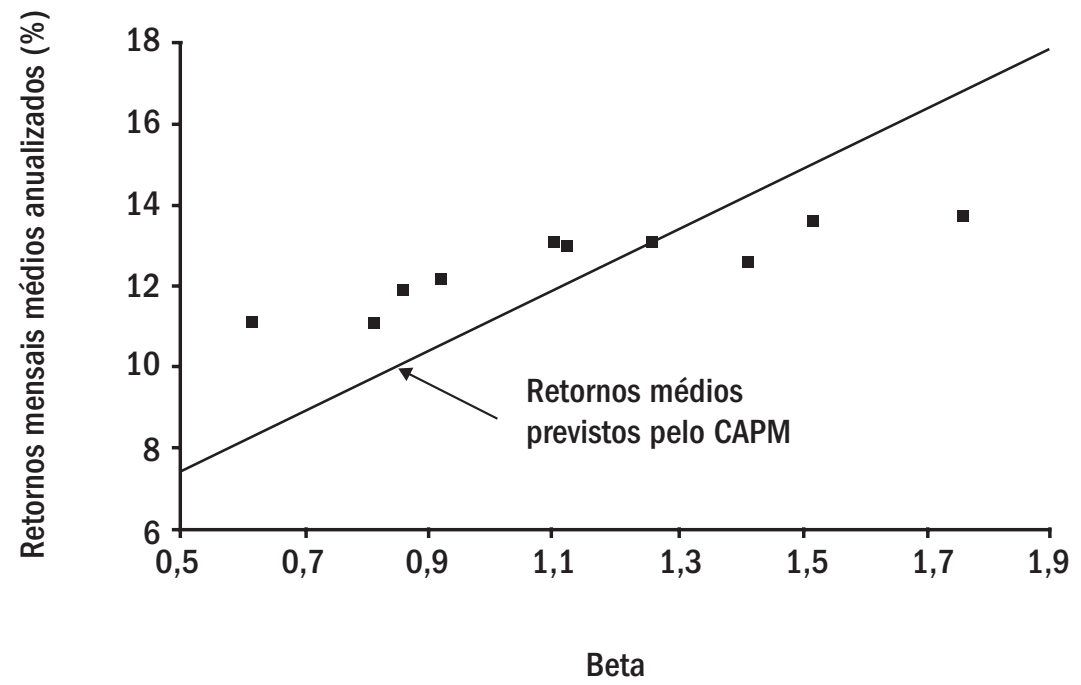


res, a relação entre beta e retorno médio das dez carteiras é muito menos inclinada do que prevê o CAPM SharpeLintner. Os retornos das carteiras de baixo beta são elevados demais e os das de beta elevado são baixos demais. Por exemplo, o retorno previsto da carteira de menor beta é de $8,3 \%$ ao ano; o retorno efetivo é de $11,1 \%$. O retorno previsto da carteira de mais alto beta é de $16,8 \%$ ao ano; o efetivo é de $13,7 \%$.

Embora o prêmio observado por unidade de beta seja menor do que prevê o modelo Sharpe-Lintner, a relação entre retorno médio e beta da Figura 2 é grosseiramente linear. Isso condiz com a versão Black do CAPM, que prevê apenas que o prêmio do beta seja positivo. Mesmo esse modelo menos restritivo, contudo, acaba sucumbindo perante os dados.

\section{Testando se os betas de mercado explicam os retornos esperados}

As versões Sharpe-Lintner e Black do CAPM têm em comum a previsão de que a carteira de mercado é eficiente em média-variância. Isso implica que as diferenças de retorno esperado entre títulos e carteiras sejam inteiramente explicadas por diferenças de beta de mercado; as demais variáveis nada devem acrescentar à explicação do retorno esperado. Essa previsão desempenha uma função relevante nos testes do CAPM. Nos primeiros trabalhos, a ferramenta preferida é a regressão longitudinal.

O arcabouço de Fama e MacBeth (1973) simplesmente acrescenta variáveis explicativas predeterminadas às regressões longitudinais mês a mês dos retornos sobre beta. Se todas as diferenças de retorno esperado forem explicadas pelo beta, as inclinações médias das variáveis adicionais não devem ser consistentemente diferentes de zero. Evidentemente, o truque na abordagem por regressão longitudinal está em escolher variáveis adicionais específicas que tendam a expor quaisquer problemas da previsão do CAPM de que, sendo a carteira de mercado eficiente, os betas de mercado possam explicar os retornos esperados do ativo.

Por exemplo, em Fama e MacBeth (1973) as variáveis adicionais são os quadrados dos betas de mercado (para testar a previsão de que a relação entre retorno esperado e beta seja linear) e as variâncias residuais de regressões dos retornos em relação ao retorno do mercado (para testar a previsão de que o beta de mercado seja a única medida de risco necessária para explicar os retornos esperados). Essas variáveis não acrescentam à explicação dos retornos médios fornecida pelo beta. Assim, os resultados de Fama e MacBeth (1973) condizem com a hipótese de que o que usam como proxy do mercado - uma carteira de igual peso de ações cotadas na Bolsa de Nova York - está na fronteira de variância mínima.

A hipótese de que os betas de mercado explicam integralmente os retornos esperados também pode ser testada com regressões de série temporal. Na regressão de série temporal descrita anteriormente (retorno excedente sobre o ativo $i$ em relação ao retorno excedente do mercado), o intercepto é a diferença entre o retorno excedente médio do ativo e o retorno excedente previsto pelo modelo Sharpe-Lintner, ou seja, beta vezes o retorno excedente médio do mercado. Se o modelo se sustentar, não haverá maneira de agrupar ativos em carteiras cujos interceptos sejam consistentemente diferentes de zero. Por exemplo, os interceptos de uma carteira de ações com elevados múltiplos preço-lucro e de uma carteira de ações com baixos múltiplos preço-lucro deveriam ser zero. Assim, para testar a hipótese de que os betas de mercado bastam para explicar os retornos esperados, estimamos a regressão de série temporal de um conjunto de ativos (ou carteiras) e então testamos conjuntamente o vetor dos interceptos de regressão em relação a zero. O truque, nesta abordagem, está em escolher os ativos (ou carteiras) do lado esquerdo de maneira que tenda a expor quaisquer falhas da previsão do CAPM de que os betas de mercado bastem para explicar os retornos esperados do ativo.

Nas primeiras aplicações, os pesquisadores usaram diversos testes para determinar se os interceptos de um conjunto de regressões de série temporal eram todos zero. Os testes têm as mesmas propriedades assintóticas, mas há divergências a respeito de qual traz as melhores propriedades em termos de pequenas amostras. Gibbons, Ross e Sbanken (1989) encerraram a discussão fornecendo um teste-F dos interceptos que tem propriedades precisas de amostra de pequeno porte. Também demonstram que o teste tem uma interpretação econômica simples. Com efeito, o teste constrói uma candidata à carteira tangente $T \mathrm{da}$ Figura 1, combinando otimamente o proxy de mercado e os ativos do lado esquerdo das regressões de série temporal. Os pesquisadores testam, então, se o conjunto eficiente fornecido pela combinação dessa carteira tangente com o ativo livre de risco é consistentemente superior à obtida com a combinação do ativo livre de risco com o proxy de mercado por si só. Em outras palavras, as estatísticas de Gibbons, Ross e Shanken testam se o proxy de mercado é a carteira tangente do conjunto de carteiras que pode ser construído por meio da combinação da carteira de mercado com os ativos específicos usados como variáveis dependentes nas regressões de série temporal.

Com o esclarecimento oferecido por essa explicação de Gibbons, Ross e Sbanken (1989), é possível perceber 
uma interpretação semelhante do teste de regressão longitudinal usado para determinar se os betas de mercado bastam para explicar retornos esperados. Nesse caso, o teste verifica se as variáveis explicativas adicionais em uma regressão longitudinal identificam padrões dos retornos sobre os ativos do lado esquerdo que não são explicados pelos betas de mercado dos ativos. Isso equivale a testar se o proxy de mercado está na fronteira de variância mínima que podemos construir usando o proxy de mercado e os ativos do lado esquerdo incluídos nos testes.

Uma lição importante dessa discussão é que, estritamente falando, as regressões de série temporal e longitudinais não testam o CAPM. Literalmente, o que se testa é se um proxy específico da carteira de mercado (normalmente uma carteira de ações ordinárias americanas) é eficiente no conjunto de carteiras que se pode construir a partir dele e dos ativos do lado esquerdo usados no teste. Seria possível concluir que o CAPM nunca foi testado e que as perspectivas de que venha a sê-lo não são boas. Isso porque o conjunto de ativos do lado esquerdo não inclui todos os ativos negociáveis e porque os dados para uma verdadeira carteira de mercado composta de todos os ativos provavelmente estão além do nosso alcance (Roll, 1977). (Trataremos disso em maiores detalhes mais adiante). Mas essa crítica pode ser feita aos testes de qualquer modelo econômico que não tenham sido exaustivos ou que usem proxies das variáveis exigidas pelo modelo.

A conclusão dos primeiros testes de regressão longitudinal do CAPM, como Fama e MacBeth (1973), e dos primeiros testes de regressão de série temporal, como Gibbons (1982) e Stambaugh (1982) é a de que os proxies de mercado comuns parecem estar na fronteira de variância mínima. Ou seja, as previsões centrais da versão Black do CAPM, de que os betas de mercado bastam para explicar retornos esperados e de que o prêmio pelo risco do beta é positivo, parecem se sustentar. Mas a previsão mais específica do CAPM Sharpe-Lintner, de que o prêmio por unidade de beta é o retorno esperado do mercado menos a taxa de juros livre de risco, é consistentemente rejeitada.

O sucesso da versão Black do CAPM nos primeiros testes produziu um consenso no sentido de que o modelo é uma boa descrição dos retornos esperados. Esses primeiros resultados, associados à simplicidade e ao apelo intuitivo do modelo, levaram o CAPM à linha de frente das finanças.

\section{Testes recentes}

A partir do final da década de 1970, surgem trabalhos empíricos que contestam até mesmo a versão Black do CAPM.
Mais especificamente, acumulam-se evidências no sentido de que grande parte da variação do retorno esperado carece de correlação com o beta de mercado.

O primeiro golpe vem das evidências de Basu (1977) de que, quando ações ordinárias são classificadas por índices preço-lucro, os retornos futuros de ações de P/L elevado são mais altos do que prevê o CAPM. Banz (1981) documenta um efeito-porte: quando as ações são classificadas por capitalização no mercado (preço vezes número de ações em circulação), os retornos médios de ações pequenas são maiores do que prevê o CAPM. Bhandari (1988) conclui que altas proporções dívida/patrimônio líquido (valor escritural da dívida dividido pelo valor de mercado do patrimônio, uma medida de alavancagem) estão associadas a retornos por demais elevados em relação aos seus betas de mercado. Finalmente, Statnan (1980) e Rosenberg, Reid e Lanstein (1985) documentam que ações com elevados índices valor escritural/valor de mercado (B/M, a proporção entre o valor escritural de uma ação ordinária e seu valor de mercado) têm elevados retornos médios que não são captados por seus betas.

Há um elemento comum às contradições do CAPM resumidas acima. Índices que envolvem os preços das ações trazem informações sobe os retornos esperados que escapam aos betas de mercado. Pensando melhor, isso não surpreende. O preço de uma ação não depende apenas do fluxo de caixa esperado que fornece, mas também dos retornos esperados que descontam ao presente os fluxos de caixa esperados. Assim, em princípio, o corte longitudinal dos preços traz informações a respeito do corte longitudinal dos retornos esperados (um elevado retorno esperado implica em uma elevada taxa de desconto e num baixo preço). O corte longitudinal dos preços das ações é, contudo, afetado arbitrariamente por diferenças de escada (ou unidade). Mas com uma escolha cuidadosa da variável de escala $X$, a razão $X / P$ pode revelar diferenças no corte longitudinal dos retornos esperados das ações. Essas razões são, assim, fortes candidatas a expor as falhas dos modelos de precificação de ativos - no caso do CAPM, falhas da previsão de que os betas de mercado bastam para explicar retornos esperados (Ball, 1978). As contradições do CAPM, acima resumidas, sugerem que os índices preço-lucro, dívida-patrimônio líquido e escritural-mercado, de fato preenchem essa função.

Fama e French (1992) atualizam e sintetizam as evidências sobre as falhas empíricas do CAPM. Usando a abordagem por regressão longitudinal, confirmam que o porte e os índices preço-lucro, dívida-patrimônio líquido e escritural-mercado somam-se à explicação dos retornos esperados das ações fornecida pelo beta de mercado. Fama 
e French (1996) chegam à mesma conclusão usando a abordagem por regressão de série temporal aplicada a carteiras de ações classificadas por índices de preço. Eles também concluem que diferentes índices de preço trazem, em grande medida, as mesmas informações sobre retornos esperados. Isso não surpreende, dado que o preço é o vetor comum dos índices de preço e os numeradores são meras variáveis de escala usadas para extrair as informações sobre retornos esperados que há no preço.

Fama e French (1992) também confirmam as evidências (Reinganum, 1981; Stambaugh, 1982; Lakonishok e Shapiro, 1986) de que a relação entre retorno médio e beta das ações ordinárias é ainda mais horizontal após os períodos de amostra usados nos primeiros trabalhos empíricos sobre CAPM. A estimativa do prêmio do beta é, contudo, turvada pela incerteza estatística (um grande erro padrão). Kothari, Shanken e Sloan (1995) procuram ressuscitar o CAPM de Sharpe-Lintner argumentando que a fraca relação entre retorno médio e beta é mero resultado do acaso. Mas as fortes evidências de que outras variáveis captam a variação do retorno esperado que escapa ao beta torna irrelevante esse argumento. Se os betas não bastam para explicar retornos esperados, a carteira de mercado não é eficiente e o CAPM perde o sentido. Evidências sobre o porte do prêmio do mercado nem salvam o modelo, nem agravam sua condenação.

A síntese das evidências sobre os problemas empíricos do CAPM fornecidas por Fama e French (1992) serve como um catalisador, marcando o ponto a partir do qual é genericamente aceito que o CAPM sofre de problemas potencialmente fatais. A pesquisa se volta, então, para a procura de explicações.

Uma possibilidade é de que os problemas do CAPM sejam espúrios, resultado de dragagem de dados - pesquisadores famintos por publicações que varrem os dados em busca de contradições que ocorrem por força do acaso em amostras específicas. Uma resposta comum a essa preocupação é fazer testes buscando conclusões semelhantes em amostras diferentes. Chan, Hamao e Lakonishok (1991) encontraram uma forte relação entre a razão escrituralmercado das ações (B/M) e o retorno médio de ações japonesas. Capaul, Rowley e Sharpe (1993) observam um efeito semelhante em quatro mercados de ações europeus e no Japão. Fama e French (1998) revelam que os índices de preço que produzem problemas para o CAPM nos Estados Unidos se apresentam de forma semelhante nos rendimentos das ações de 12 outros grandes mercados e nos de mercados emergentes. Essas evidências sugerem que as contradições do CAPM associadas a índices de preço não ocorrem apenas em amostras específicas.

\section{Explicações: precificação irracional ou risco}

Entre aqueles que concluem pela fatalidade das falhas empíricas do CAPM, predominam duas escolas. De um lado estão os comportamentalistas. Sua perspectiva se baseia em evidências de que ações com elevadas razões entre valor escritural e preço de mercado costumam ser de empresas em dificuldades, ao passo que um baixo B/M está associado a empresas em crescimento (Lakonishok, Shleifer e Vishny, 1994; Fama e French, 1995). Os comportamentalistas argumentam que classificar as empresas por seu índice escritural-mercado expõe a reação excessiva do investidor a boas e más circunstâncias. Os investidores extrapolam o desempenho passado, resultando em um preço de ação muito elevado para empresas em crescimento (baixo $\mathrm{B} / \mathrm{M}$ ) e muito alto para empresas em dificuldades (elevado B/M, também chamadas "empresas de valor"). Quando essa reação excessiva finalmente se corrige, resultam retornos elevados para as ações de valor e retornos baixos para as ações de empresas em crescimento. Entre os defensores desse ponto de vista, estão DeBondt e Thaler (1987), Lakonishok, Shleifer e Vishny (1994) e Haugen (1995).

A segunda possibilidade de explicação das contradições empíricas do CAPM indica a necessidade de um modelo mais complexo de precificação de ativos. O CAPM se baseia em muitas premissas irreais. Por exemplo, a de que os investidores somente se preocupam com a média e a variância do retorno da carteira em um período é bastante exagerada. É razoável que eles também se importem com a maneira como o retorno de sua carteira covaria em relação ao rendimento do trabalho e a oportunidades futuras de investimento, de modo que a variância do retorno de uma carteira deixa escapar importantes dimensões do risco. Se assim for, o beta de mercado não é uma descrição completa do risco de um ativo, e não devemos nos surpreender ao perceber que diferenças de retorno esperado não são plenamente explicadas pelas diferenças de beta. Segundo esse ponto de vista, a pesquisa deveria se voltar para modelos de precificação de ativos que expliquem melhor os retornos médios.

O modelo intertemporal de precificação de ativos de capital (ICAPM) de Merton (1973) é um prolongamento natural do CAPM. O ICAPM parte de uma premissa diferente a respeito dos objetivos dos investidores. No CAPM, os investidores só se preocupam com a riqueza que sua carteira produz ao fim do período em andamento. No ICAPM, os investidores se importam não só com o payoff ao fim do período, mas, também, com as oportunidades que terão de consumir ou investir esse payoff. Assim, ao escolher uma carteira no momento $t$ - 1 , os investidores 
do ICAPM consideram como sua riqueza no momento $t$ poderia variar com variáveis de estado futuras, inclusive renda do trabalho, os preços dos bens de consumo e a natureza das oportunidades de carteira em $t$, e as expectativas sobre renda do trabalho, consumo e oportunidades de investimento disponíveis após $t$.

Assim como os investidores do CAPM, os do ICAPM preferem um elevado retorno esperado e uma baixa variância do retorno. Mas os investidores do ICAPM também estão preocupados com as covariâncias do retorno da carteira em relação a variáveis de estado. Assim, as carteiras ótimas são "multifatorialmente eficientes", o que significa que têm os mais elevados retornos esperados possíveis, dado as variâncias de seus retornos e as covariâncias de seus retornos em relação às variáveis de estado relevantes.

Fama (1996) demonstra que o ICAPM generaliza a lógica do CAPM. Ou seja, se há tomada e concessão de empréstimos à taxa livre de risco ou se for permitida a venda short dos ativos de risco, os preços a que o mercado fecha implicam que a carteira de mercado seja multifatorialmente eficiente. Ademais, a eficiência multifatorial implica uma relação entre retorno esperado e riscos do beta, mas exige betas adicionais, além de um beta de mercado, para explicar os retornos esperados.

Uma implementação ideal do ICAPM seria especificar as variáveis de estado que afetam os retornos esperados. Fama e French (1993) adotam uma abordagem mais indireta, talvez mais ao estilo da teoria da precificação por arbitragem de Ross (1976). Argumentam que, embora o porte e a razão escritural-mercado não sejam em si variáveis de estado, os maiores retornos médios de ações de pequeno porte e de elevado índice escritural-mercado refletem variáveis de estado não identificadas. Estas produzem riscos não diversificáveis (covariâncias) em retornos que não são captados pelo retorno do mercado e são precificados separadamente dos betas de mercado. Para sustentar esse argumento, demonstram que os retornos das ações de pequenas empresas covariam mais uma com as outras do que com os retornos de ações de empresas de grande porte e que os retornos de ações de elevado índice escritural-mercado (ações de valor) covariam mais entre si do que com os retornos de ações de baixo índice escritural-mercado (ações de crescimento). Fama e French (1995) demonstram que há padrões semelhantes de porte e índice escritural-mercado na covariação de fundamentos como lucro e faturamento.

Com base nessas evidências, Fama e French (1993, 1996) propõem um modelo trifatorial de retornos esperados:

$$
\begin{array}{ll}
\text { (Modelo trifatorial) } & E\left(R_{i t}\right)-R_{f t}=\beta_{i M}\left[E\left(R_{M t}\right)-R_{f t}\right] \\
& +\beta_{i s} E\left(S M B_{t}\right)+\beta_{i h} E\left(H M L_{t}\right)
\end{array}
$$

Nessa equação, $S M B_{1}$ (small minus big = pequeno menos grande) é a diferença entre os retornos de carteiras diversificadas de ações de empresas pequenas e grandes; HML1 (high minus low = alto menos baixo) é a diferença entre os retornos de carteiras diversificadas de ações de índice escritural-mercado alto e baixo; e os betas são inclinações da regressão múltipla de $R_{i t}-R_{f t}$ em relação a $R_{\mathrm{Mt}}-R_{f t}, S M B_{t}$ e $H M L_{t}$.

Para fins de comparação, o valor médio do ágio de mercado $R_{\mathrm{Mi}}-R_{\mathrm{ft}}$ do período $1927-2003$ é de $8,3 \%$ ao ano, ou 3,5 erros padrão distante de zero. Os valores médios de $S M B_{t}$ e $H M L_{t}$ são de 3,6\% e 5,0\% ao ano, encontrando-se a 2,1 e 3,1 erros padrão de distância de zero. Os três prêmios são voláteis, com desvios padrão anuais de 21,0\% $\left(R_{M t}-R_{f t}\right), 14,6 \%\left(S M B_{t}\right)$ e $14,2 \%\left(H M L_{t}\right)$ ao ano. Embora o valor médio dos prêmios seja elevado, a alta volatilidade também implica substancial incerteza quanto aos verdadeiros prêmios esperados.

Uma implicação da equação de retorno esperado do modelo trifatorial é que o intercepto $\alpha_{i}$ da regressão de série temporal

$$
R_{i t}-R_{f t}=\alpha_{i}+\beta_{i M}\left(R_{M i}-R_{f t}\right)+\beta_{i s} S M B_{t}+\beta_{i h} H M L_{t}+\varepsilon_{i t}
$$

é zero para todos os ativos i. Usando esse critério, Fama e French $(1993,1996)$ concluem que o modelo capta grande parte da variação do retorno médio de carteiras formadas com base em porte, índice escritural-mercado e outros índices de preço que causam problemas para o CAPM. Fama e French (1998) demonstram que uma versão internacional do modelo tem melhor desempenho do que um CAPM internacional no que se refere a descrever os retornos médios de carteiras formadas com base em variáveis de escala de preço com ações de 13 grandes mercados.

O modelo trifatorial é hoje amplamente utilizado em pesquisas empíricas que exigem um modelo de retornos esperados. Estimativas de $\alpha_{i}$, obtidas com a regressão de série temporal acima são usadas para calibrar a velocidade com que os preços das ações reagem a novas informações (por exemplo, Loughran e Ritter, 1995; Mitchell e Stafford, 2000). São também usadas para medir informações especiais de gestores de carteiras, como, por exemplo, no estudo de Carhart (1997) sobre desempenho de fundos mútuos. Já entre profissionais de mercado, como a Ibbotson Associates, o modelo é oferecido como alternativa ao CAPM para estimar o custo do capital social. 
Do ponto de vista teórico, o principal defeito do modelo trifatorial está em sua motivação empírica. Os retornos explicativos pequeno-menos-grande (SMB) e alto-menosbaixo (HML) não são motivados por previsões a respeito de variáveis de estado de interesse dos investidores. Pelo contrário, são construtos brutos que têm por objetivo captar a maneira como o retorno médio das ações varia com o porte e com o índice escritural-mercado.

Mas essa preocupação não é fatal. O ICAPM não exige que as carteiras adicionais, usadas com a de mercado para explicar os retornos esperados, "imitem" as variáveis de estado relevantes. Tanto no ICAPM quanto na teoria de precificação por arbitragem, basta que as carteiras adicionais sejam bem diversificadas (na terminologia de Fama, 1996, que sejam de variância mínima multifatorial) e suficientemente diferentes da carteira de mercado para captar a covariância dos retornos e a variação dos retornos esperados que escapam à carteira de mercado. Assim, acrescentar carteiras diversificadas que captem a covariação e a variação dos retornos médios que o mercado não explica condiz com o espírito tanto do ICAPM quanto da teoria de precificação por arbitragem de Ross.

Os comportamentalistas não se impressionam com as evidências em favor de uma explicação baseada em risco para as falhas do CAPM. Normalmente reconhecem que o modelo trifatorial capta a covariação dos retornos que escapa ao retorno do mercado e também grande parte dos efeitos de porte e valor sobre os retornos médios que o CAPM deixa de explicar. Mas acreditam que o prêmio de retorno médio associado ao fator escritural-mercado do modelo - que faz a maior parte do trabalho no que se refere à melhoria em relação ao CAPM - é, ele mesmo, resultado da reação excessiva do investidor que está correlacionada entre empresas de uma maneira que apenas parece estar ligada ao risco. Em suma, do ponto de vista comportamental, o mercado tenta estabelecer preços segundo o CAPM, e quaisquer divergências em relação ao CAPM se devem a erros de precificação.

O conflito entre as explicações da escola comportamentalista da precificação irracional e as da escola do risco racional para as falhas empíricas do CAPM nos deixam em um impasse já habitual. Fama (1970) enfatiza que a hipótese de que os preços refletem adequadamente as informações disponíveis deve ser testada no contexto de um modelo de retornos esperados como o CAPM. Intuitivamente, para testar se os preços são racionais, é preciso adotar uma posição a respeito do que o mercado está tentando fazer ao estabelecer preços - ou seja, o que é risco e qual a relação entre retorno esperado e risco?
Quando os testes rejeitam o CAPM, não é possível dizer se o problema está na premissa de que os preços são racionais (a visão comportamental) ou em violações de outras premissas que também são necessárias para produzir o CAPM (nossa posição).

Felizmente, para algumas aplicações, a maneira como o modelo trifatorial é usado não depende de opinião a respeito de serem os prêmios do retorno médio o resultado racional dos riscos das variáveis de estado subjacentes, o resultado de comportamento irracional do investidor ou resultados do acaso específicos da amostra. Por exemplo, ao medir a reação dos preços das ações a novas informações, ou ao avaliar o desempenho de carteiras gerenciadas, é preciso levar em conta padrões conhecidos de retorno e retorno médio no período em tela, seja qual for a sua fonte. Da mesma forma, ao estimar o custo do capital social, o pesquisador poderia não se preocupar com o fato de os prêmios pelo retorno esperado serem racionais ou irracionais, uma vez que são, de qualquer forma, parte do custo de oportunidade do capital social (Stein, 1996). Mas o custo do capital é prospectivo, de modo que, se os prêmios forem específicos da amostra, serão irrelevantes.

O modelo trifatorial não é uma panacéia. Seu defeito mais grave é o efeito-ímpeto descrito por Jegadeesh e Titman (1993). Ações com bom desempenho em relação ao mercado nos últimos 3-12 meses tendem a continuar apresentando bom desempenho nos meses seguintes, e ações de desempenho fraco tendem a continuar assim. Esse efeito-ímpeto é distinto do efeito-valor captado pelo índice escritural-mercado e outros índices de preço. Ademais, o efeito-ímpeto não é explicado pelo modelo trifatorial, nem pelo CAPM. Tomando Carhart (1997) como exemplo, uma possibilidade é acrescentar um fator de ímpeto (a diferença entre os retornos de carteiras diversificadas de ações vencedoras e perdedoras no curto prazo) ao modelo trifatorial. Novamente, esse passo é legítimo em aplicações em que a meta seja abstrair-se dos padrões conhecidos dos retornos médios para revelar efeitos especificamente ligados a determinadas informações ou a um gestor. Mas, por ser de curta duração, o efeito-ímpeto é, em grande medida, irrelevante para estimativas do custo do capital social.

Outra linha de pesquisa aponta problemas tanto no modelo trifatorial quanto no CAPM. Frankel e Lee (1998), Dechow, Hutton e Sloan (1999), Piotroski (2000) e outros demonstram que, em carteira formada a partir de índices de preço, como o escritural-mercado, ações com fluxos de caixa esperados mais elevados têm retornos médios maiores que não são captados seja pelo modelo trifatorial seja 
pelo CAPM. Os autores interpretam seus resultados como evidência de que os preços das ações são irracionais no sentido de que não refletem as informações disponíveis sobre lucratividade esperada.

Na prática, porém, não é possível dizer se o problema é uma má precificação ou um mau modelo de precificação de ativos. O preço de uma ação sempre pode ser expresso como o valor presente dos fluxos de caixa futuros esperados, descontados ao retorno esperado da ação (Campbell e Shiller, 1989; Vuolteenabo, 2002). Conclui-se daí que, se duas ações tiverem o mesmo preço, a de maior fluxo de caixa esperado deve ter maior retorno esperado. Isso se sustenta, seja a precificação racional ou irracional. Assim, quando se observa uma relação positiva entre os fluxos de caixa esperados e os retornos esperados que não é explicada pelo CAPM ou pelo modelo trifatorial, não se pode dizer se é resultado de precificação irracional ou de um modelo de precificação de ativos com erros de especificação.

\section{A questão da proxy de mercado}

Roll (1977) argumenta que o CAPM jamais foi testado e, provavelmente, jamais será. O problema é que a carteira de mercado que está no núcleo do modelo é teórica e empiricamente fugidia. Não está teoricamente claro quais ativos (por exemplo, capital humano) podem ser legitimamente excluídos da carteira de mercado e a disponibilidade de dados limita substancialmente os ativos passíveis de inclusão. Com isso, os testes do CAPM são forçados a usar proxies da carteira de mercado, testando, na prática, se as proxies estão na fronteira de variância mínima. Roll argumenta que, como os testes usam proxies e não a carteira de mercado verdadeira, nada aprendemos sobre o CAPM.

Somos mais pragmáticos. A relação entre retorno esperado e beta de mercado do CAPM é simplesmente a condição de variância mínima que se sustenta em qualquer carteira eficiente aplicada à carteira de mercado. Assim, se pudermos encontrar uma proxy de mercado que esteja na fronteira de variância mínima, ela pode ser usada para descrever diferenças de retorno esperado, e ficaríamos satisfeitos em usá-la assim. As fortes rejeições ao CAPM descritas acima, contudo, indicam que os pesquisadores ainda não encontraram uma proxy de mercado razoável que esteja próxima da fronteira de variância mínima. Se os pesquisadores estiverem limitados a proxies razoáveis, duvidamos que algum dia a encontrem.

Nosso pessimismo é alimentado por diversos resultados empíricos. Stambaugh (1982) testou o CAPM usando uma série de carteiras de mercado, entre as quais, além de ações ordinárias americanas, debêntures corporativas e governamentais, ações preferenciais, bens imóveis e outros bens de consumo duráveis. Concluiu que os testes do CAPM não são sensíveis à expansão da proxy de mercado para além das ações ordinárias, basicamente porque a volatilidade dos retornos de mercado expandidos é sobrepujada pela volatilidade dos retornos das ações.

Os resultados de Stambaugh (1982) não são necessariamente convincentes porque suas proxies de mercado se limitam a ativos dos Estados Unidos. Se os mercados de capitais internacionais são abertos e os preços dos ativos correspondem a uma versão internacional do CAPM, a carteira de mercado deve incluir ativos internacionais. Fama e French (1998) revelam, contudo, que os betas de uma carteira de mercado de ações globais não são capazes de explicar os retornos médios observados pelo mundo sobre ações com elevados índices escritural-mercado ou lucro-preço.

Um grande problema para o CAPM é que as carteiras formadas pela classificação de ações por índices de preço produzem uma ampla gama de retornos médios, mas estes não estão positivamente correlacionados com os betas de mercado (Lakonishok, Sbleifer e Vishny, 1994; Fama e French, 1996, 1998). O problema encontra-se ilustrado na Figura 3, que mostra os retornos médios e betas (calculados em referência à carteira ponderada pelo valor da CRSP de ações da NYSE, da AMEX e da NASDAQ) para o período de julho de 1963 a dezembro de 2003 de dez carteiras de ações americanas formadas anualmente com base nos valores classificados do índice escritural-mercado $(\mathrm{B} / \mathrm{M}){ }^{6}$

Os retornos médios das carteiras $\mathrm{B} / \mathrm{M}$ aumentam de maneira quase monótona de $10,1 \%$ ao ano para o grupo de menor B/M (carteira 1) até impressionantes 16,7\% para a de maior índice (carteira 10). Mas a relação positiva entre beta e retorno médio prevista pelo CAPM fica perceptivelmente ausente. Por exemplo, a carteira de menor índice escritural-mercado tem o maior beta, mas o menor retorno médio. $\mathrm{O}$ beta estimado da carteira de maior índice escritural-mercado e maior retorno médio é de apenas 0,98. Com uma taxa de juros livre de risco média anualizada, $R f$, de $5,8 \%$, e um prêmio de mercado médio anualizado, $R M$ - $R f$ de $11,3 \%$, o CAPM de SharpeLintner prevê um retorno médio de $11,8 \%$ para a carteira de menor $\mathrm{B} / \mathrm{M}$, e $11,2 \%$ para a de maior índice, valores distantes dos observados de $10,1 \%$ e $16,7 \%$. Para que o modelo Sharpe-Lintner "funcione" com essas carteiras, seus betas de mercado precisam mudar incrivelmente de 1,09 para 0,78 , no caso da de menor B/M, e de 0,98 para 1,98 , no caso da de maior índice. Consideramos impro- 
vável que proxies alternativas da carteira de mercado produzam betas e um prêmio de mercado capaz de explicar os retornos médios dessas carteiras.

É sempre possível que pesquisadores redimam o CAPM, encontrando uma proxy razoável para a carteira de mercado que esteja na fronteira de variância mínima. Enfatizamos, contudo, que essa possibilidade não pode ser usada para justificar a maneira como o CAPM tem sido aplicado. O problema é que as aplicações costumam usar as mesmas proxies de mercado, como a carteira ponderada pelo valor de ações americanas, que levam a rejeições do modelo em testes empíricos. As contradições do CAPM observadas quando usadas tais proxies em testes do modelo revelam-se más estimativas dos retornos esperados nas aplicações - por exemplo, estimativas do custo do capital que são por demais baixas (em relação aos retornos médios históricos) para ações pequenas e ações com elevado índice escritural-mercado. Em suma, se uma proxy de mercado não funciona nos testes do CAPM, também não funciona na aplicação.

\section{CONCLUSÃO}

A versão do CAPM desenvolvida por Sharpe (1964) e Lintner (1965) nunca teve sucesso empírico. Nos primeiros trabalhos empíricos, a versão Black (1972) do modelo, que é capaz de acomodar um tradeoff mais horizontal do retorno médio pelo beta de mercado, obteve algum suces- so. Mas, no final da década de 1970, a pesquisa começou a revelar variáveis como porte, diversos índices de preço e ímpeto, que se somam à explicação dos retornos médios fornecida pelo beta. Os problemas são graves o bastante para invalidar a maioria das aplicações do CAPM.

Por exemplo, os livros-texto de finanças freqüentemente recomendam usar a relação risco-retorno do CAPM de Sharpe-Lintner para estimar o custo do capital social. O que se prescreve é estimar o beta de mercado de uma ação e combiná-lo com a taxa de juros livre de risco e com o prêmio pelo risco médio do mercado para produzir uma estimativa do custo do patrimônio. A carteira de mercado típica nesses exercícios inclui apenas ações ordinárias americanas. Mas trabalhos empíricos tanto antigos quanto recentes nos dizem que a relação entre beta e retorno médio é mais horizontal do que prevê a versão SharpeLintner do CAPM. Com isso, as estimativas do CAPM de custo do patrimônio para ações de beta elevado são altas demais (em relação aos retornos médios históricos) e as estimativas das ações de betas baixos são baixas demais (Friend e Blume, 1970). Nesse mesmo sentido, se os elevados retornos médios sobre ações de valor (de elevado índice escritural-mercado) implicam os elevados retornos esperados, as estimativas de custo do patrimônio do CAPM para essas ações são baixas demais. ${ }^{7}$

O CAPM também é freqüentemente usado para medir o desempenho de fundos mútuos e outras carteiras gerenciadas. A abordagem, que data de Jensen (1968), é estimar a regressão de série temporal de uma carteira

Figura 3 - Retornos Mensais Médios Anualizados e Beta de Carteiras Ponderadas pelo Valor Formadas com Base no B/M, 1963-2003.

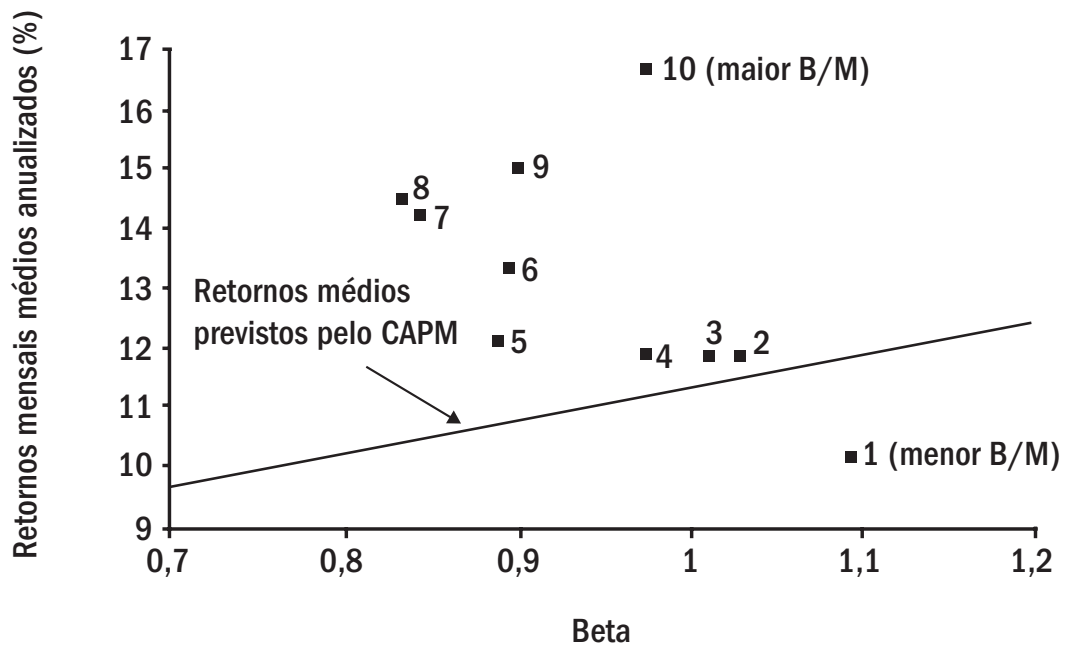


pelo CAPM e usar o intercepto (alfa de Jensen) para medir o desempenho anormal. O problema é que, por causa das falhas empíricas do CAPM, até carteiras gerenciadas passivamente podem produzir retornos anormais se suas estratégias de investimento envolverem tendências em direção a problemas do CAPM (Elton, Gruber, Das e Hlavka, 1993). Por exemplo, fundos que se concentrem em ações de baixo beta, ações de pequeno porte, ou ações de valor tenderão a produzir retornos anormais positivos em relação às previsões do CAPM de Sharpe-Lintner, ainda que os gestores do fundo não tenham especial talento para escolher ações vencedoras. O CAPM, como o modelo de carteira de Markowitz (1952, 1959) em que se baseia, ainda assim é um tour de force teórico. Continuamos a ensinar o CAPM como uma introdução aos conceitos fundamentais da teoria das carteiras e da precificação de ativos a ser posteriormente desenvolvida com modelos mais complicados, como o ICAPM, de Merton (1973). Mas também alertamos nossos alunos para o fato de que, apesar de sua atraente simplicidade, os problemas empíricos do CAPM provavelmente invalidam seu uso em aplicações práticas.

\section{AGRADECIMENTO}

Os autores agradecem os comentário de John Cochrane, George Constantinides, Richard Leftwich, Andrei Shleifer, Rene Stulz e Timothy Taylor.

\section{NOTAS}

${ }^{1}$ Embora qualquer modelo de precificação de ativos seja um modelo de precificação de ativos de capital, a profissão das finanças reserva a sigla CAPM especificamente para os modelos de Sharpe (1964), Lintner (1965) e Black (1972) aqui discutidos. Assim, neste artigo nos referiremos ao modelo Sharpe-Lintner-Black como CAPM.

${ }^{2}$ Formalmente, o retorno, o retorno esperado e o desvio padrão do retorno de carteiras compostas do ativo livre de risco $f$ e da carteira de risco g variam $\operatorname{com} x$, a proporção de fundos da carteira investidos em $f$, sendo

$R_{p}=x R_{f}+(1-x) R_{g}$

$E\left(R_{p}\right)=x R_{f}+(1-x) E\left(R_{g}\right)$,

$\sigma\left(R_{p}\right)=(1-x) \sigma\left(R_{g}\right), x \leq 1,0$,

que, juntos, implicam que as carteiras se localizam ao longo da linha que passa por $R_{f}$ e $g$ na Figura 1 .
${ }^{3}$ Formalmente, se $X i_{M}$ for o peso do ativo i na carteira de mercado, a variância do retorno da carteira será

$\sigma^{2}\left(R_{M}\right)=\operatorname{Cov}\left(R_{M}, R_{M}\right)=\operatorname{Cov}\left(\sum_{i=1}^{N} x_{i M} R_{i}, R_{M}\right)=\sum_{i=1}^{N} x_{i M} \operatorname{Cov}\left(R_{i}, R_{M}\right)$

${ }^{4}$ Formalmente, se $x_{\mathrm{ip}}, i=1, \ldots, \mathrm{N}$ forem os pesos dos ativos em uma carteira $p$, o retorno e o beta de mercado esperados da carteira estarão relacionados com o retorno esperado e os betas dos ativos como em

$E\left(R_{p}\right)=\sum_{i=1}^{N} x_{i p} E\left(R_{i}\right)$ e $\beta_{p M}=\sum_{i=1}^{N} x_{i p} \beta_{p M}$.

Assim, a relação CAPM entre retorno esperado e beta,

$E\left(R_{i}\right)=R\left(R_{f}\right)+\left[E\left(R_{M}\right)-E\left(R_{f}\right)\right] \beta_{i M}$

se sustenta tanto quando o ativo $i$ é uma carteira como quando é um título individual.

${ }^{5}$ Para ser incluído na amostra do ano $t$, um título deve dispor de dados de mercado (preço vezes ações em circulação) para dezembro de $t$ - 1 e ser classificado como ação ordinária pelo CRSP. Assim, excluímos títulos como American Depository Receipts (ADRs) e Real Estate Investment Trusts (REITs).

\footnotetext{
${ }^{6}$ Os dados de retorno de ações vêm do CRSP e os de valor escritural da Compustat e dos manuais de Indústria, Transportes, Serviços Públicos e Instituições Financeiras da Moody's. As ações são alocadas a dez carteiras ao fim de junho de cada ano (1963 a 2003) usando a razão entre o valor escritural do ano fiscal encerrado $n$ ano-calendário $t$ - 1 e o valor de mercado da ação no fim de dezembro de $t-1$. Valor escritural é o valor escritural do capital acionário mas impostos diferidos constantes do balanço e créditos fiscais de investimentos (se disponíveis), menos o valor escritural das ações ordinárias. Dependendo da disponibilidade, usamos o valor de resgate, liquidação ou ao par (nessa ordem) para estimar o valor escritural das ações ordinárias. O capital acionário é o valor relatado pela Moody's ou pela Compustat, se disponível. Do contrário, medimos o capital acionário como sendo o valor escritural das ações ordinárias mais o valor ao par das ações preferenciais ou o valor escritural do ativo menos o passivo total (nessa ordem). As carteiras do ano $t$ incluem ações cotadas na NYSE (1963-2003), na AMEX (1963-2003) e na NASDAQ (1972-2003) com valor escritural positivo em $t$ - 1 e valor de mercado (extraído do CRSP) positivo em dezembro de $t-1$ e junho de $t$. As carteiras excluem títulos que o CRSP não classifique como ações ordinárias. Os pontos de quebra do ano $t$ utilizam apenas títulos que constem da NYSE em junho do ano $t$.
}

\footnotetext{
${ }^{7}$ Os problemas aumentam por causa dos grandes erros padrão das estimativas do prêmio de mercado e dos betas de ações individuais, o que provavelmente basta para fazer com que as estimativas de custo do patrimônio pelo CAPM não tenham significado, mesmo que o CAPM se sustente (Fama e French, 1997; Pastor e Stambaugh, 1999). Por exemplo, usando a taxa da T-bill como taxa de juros livre de risco e a carteira de ações ordinárias negociadas em bolsa ponderada pelo valor do CRSP, o valor médio do prêmio do patrimônio RMi - Rp para o período 1927 2003 é de 8,3\% ao ano, com erro padrão de 2,4\%. A faixa de dois erros padrão vai, portanto, de $3,5 \%$ a $13,1 \%$, o que basta para fazer com que qualquer projeto tanto possa parecer lucrativo quanto não lucrativo. Esse problema, contudo, não é específico do CAPM. Por exemplo, os retornos esperados de todas as versões do ICAPM de Merton (1973) incluem um beta de mercado e o prêmio de mercado esperado. Além disso, como observamos anteriormente, os valores esperados dos prêmios de porte e escritural-mercado pelo modelo trifatorial de Fama-French também são estimativas com erros substanciais.
} 
Artigo originalmente publicado por Eugene F. Fama e Kenneth R. French, sob o título "The Capital Asset Pricing Model Theory And Evidence", no Journal of Economic Perspectives, v. 18, n. 3, p.25-46, 2004. Publicado com autorização da American Economic Association. (C)American Economic Association. http://www.aeaweb.org.

\section{REFERÊNCIAS}

BALL, R. Anomalies in relationships between securities' yields and yieldsurrogates. Journal of Financial Economics, v. 6, n. 2, p. 103-126, 1978.

BANZ, R. W. The relationship between return and market value of common stocks. Journal of Financial Economics, v. 9, n. 1, p. 3-18, 1981.

BASU, S. Investment performance of common stocks in relation to their price-earnings ratios: a test of the efficient market hypothesis. Journal of Finance, v. 12, n. 3, p. 129-56, 1977.

BHANDARI, L. C. Debt/equity ratio and expected common stock returns: empirical Evidence. Journal of Finance, v. 43, n. 2, p. 507-528, 1988.

BLACK, F. Capital market equilibrium with restricted borrowing. Journal of Business, v. 45, n. 3, p. 444-454, 1972.

BLACK, F; JENSEN, M. C.; SCHOLES, M. The capital asset pricing model: some empirical tests. In: JENSEN, M. C. (Ed.). Studies in the Theory of Capital Markets. New York: Praeger, 1972. p. 79-121.

BLUME, M. Portfolio theory: a step towards its practical application. Journal of Business, v. 43, n. 2, p. 152-174, 1970.

BLUME, M.; FRIEND, I. A new look at the capital asset pricing model. Journal of Finance, v. 28, n. 1, p. 19-33, 1973.

CAMPBELL, J.; SHILLER, R. J. The dividend-price ratio and expectations of future dividends and discount factors. Review of Financial Studies, v. 1, n. 3, p. 195-228, 1989.

CAPAUL, C.; ROWLEY, I.; SHARPE, W. F. International value and growth stock returns. Financial Analysts Journal, v. 49, n. 1, p. 27-36, jan./fev. 1993.

CARHART, M. M. On persistence in mutual fund performance. Journal of Finance, v. 52, n. 1, p. 57-82, 1997.

CHAN, L. K. C.; HAMAO, Y.; LAKONISHOK, J. Fundamentals and stock returns in Japan. Journal of Finance, v. 46, n. 5, p. 1739-1789, 1991.

DEBONDT, W. F. M.; THALER, R. H. Further evidence on investor overreaction and stock market seasonality. Journal of Finance, v. 42, n. 3, p. 557-581, 1987.
DECHOW, P. M.; HUTTON, A. P.; SLOAN, R. G. An empirical assessment of the residual income valuation model. Journal of Accounting and Economics, v. 26, n. 1, p. 1-34, 1999.

DOUGLAS, G. W. Risk in the Equity Markets: An Empirical Appraisal of Market Efficiency. Ann Arbor, Michigan: University Microfilms, Inc. 1968.

ELTON, E. J.; GRUBER, M. J.; DAS, S.; HLAVKA, M. Efficiency with costly information: a reinterpretation of evidence from managed portfolios. Review of Financial Studies, v. 6, n. 1, p. 1-22, 1993.

FAMA, E. F. Efficient capital markets: a review of theory and empirical work. Journal of Finance, v. 25, n. 2, p. 383-417, 1970.

FAMA, E. F. Multifactor portfolio efficiency and multifactor asset pricing. Journal of Financial and Quantitative Analysis, v. 31, n. 4, p. 441-465, 1996.

FAMA, E. F; FRENCH, K. R. The cross-section of expected stock returns. Journal of Finance, v. 47, n. 2, p. 427-465, 1992.

FAMA, E. F; FRENCH, K. R. Common risk factors in the returns on stocks and bonds. Journal of Financial Economics, v. 33, n. 1, p. 3-56, 1993.

FAMA, E. F; FRENCH, K. R. Size and book-to-market factors in earnings and returns. Journal of Finance, v. 50, n. 1, p. 131-155, 1995.

FAMA, E. F; FRENCH, K. R. Multifactor explanations of asset pricing Anomalies. Journal of Finance, v. 51, n. 1, p. 55-54, 1996.

FAMA, E. F; FRENCH, K. R. Industry costs of equity. Journal of Financial Economics, v. 43, n. 2, p. 153-193, 1997.

FAMA, E. F; FRENCH, K. R. Value versus growth: the international evidence. Journal of Finance, v. 53, n. 6, p. 1975-1999, 1998.

FAMA, E. F; MACBETH, J. D. Risk, return, and equilibrium: empirical tests. Journal of Political Economy, v. 81, n. 3, p. 607-636, 1978.

FRANKEL, R.; LEE, C. M. C. Accounting valuation, market expectation, and cross-sectional stock returns. Journal of Accounting and Economics, v. 25, n. 3, p. 283-319, 1998.

FRIEND, I.; BLUME, M. Measurement of portfolio performance under uncertainty. American Economic Review, v. 60, n. 4, p. 607-636, 1970

GIBBONS, M. R. Multivariate tests of financial models: a new approach. Journal of Financial Economics, v. 10, n. 1, p. 3-27, 1982.

GIBBONS, M. R.; ROSS, S. A.; SHANKEN, J. A test of the efficiency of a given portfolio. Econometrica, v. 57, n. 5, p. 1121-1152, 1989.

HAUGEN, R. The New Finance: The Case against Efficient Markets. Englewood Cliffs, NJ; Prentice Hall, 1995.

JEGADEESH, N.; TITMAN, S. Returns to buying winners and selling losers: implications for stock market efficiency. Journal of Finance, v. 48, n. 1, p. 65-91, 1993.

JENSEN, M. C. The performance of mutual funds in the period 1945-1964. Journal of Finance, v. 23, n. 2, p. 389-416, 1968. 
KOTHARI, S. P.; SHANKEN, J.; SLOAN, R. G. Another look at the crosssection of expected stock returns. Journal of Finance, v. 50, p. 1, p. 185224, 1995

LAKONISHOK, J.; SHAPIRO, A. C. Systematic risk, total risk, and size as determinants of stock market returns. Journal of Banking and Finance, v. 10, n. 1, p. 115-132. 1986.

LAKONISHOK, J.; SHLEIFER, A.; VISHNY, R. W. Contrarian investment, extrapolation, and risk. Journal of Finance, v. 49, n. 5, p. 1541-1578, 1994.

LINTNER, J. The valuation of risk assets and the selection of risky investments in stock portfolios and capital budgets. Review of Economics and Statistics, v. 47, n. 1, p. 13-37, 1965.

LOUGHRAN, T.; RITTER, J. R. The New Issues Puzzle. Journal of Finance, v. 50, n. 1, p. 23-51, 1995.

MARKOWITZ, H. Portfolio selection. Journal of Finance, v. 7, n.1, p. 7799, 1952.

MARKOWITZ, H. Portfolio Selection: Efficient Diversification of Investment. Cowles Foundation Monograph, n. 16. New York: John Wiley E Sons, Inc, 1959.

MERTON, R. C. An intertemporal capital asset pricing model. Econometrica, v. 41, n. 5 , p. $867-887,1973$.

MILLER, M.; SCHOLES, M. Rates of return in relation to risk: a reexamination of some recent findings. In: JENSEN, M. C. (Ed.). Studies in the Theory of Capital Markets. New York: Praeger, 1972. p. 47-78.

MITCHELL, M. L.; STAFFORD, E. Managerial decisions and long-term stock price performance. Journal of Business, v. 73, n. 3, p. 287-329, 2000.

PASTOR, L.; STAMBAUGH, R. F. Costs of equity capital and model mispricing. Journal of Finance, v. 54, n. 1, p. 67-121, 1999.
PIOTROSKI, J. D. Value investing: the use of historical financial statement information to separate winners from losers. Journal of Accounting Research, v. 38, Supplement: Studies on Accounting Information and the Economics of the Firm, p. 1-41, 2000.

REINGANUM, M. R. A New empirical perspective on the CAPM. Journal of Financial and Quantitative Analysis, v. 16, n. 4, p. 439-462, 1981.

ROLL, R. A critique of the asset pricing theory's tests' part i: on past and potential testability of the theory. Journal of Financial Economics, v. 4, n. 2, p. 129-176, 1977.

ROSENBERG, B.; REID, K.; LANSTEIN, R. Persuasive evidence of market inefficiency. Journal of Portfolio Management, v. 11, n. 3, p. 9-17, Spring, 1985

ROSS, S. A. The arbitrage theory of capital asset pricing. Journal of Economic Theory, v. 13, n. 3, p. 341-360. 1976.

SHARPE, W. F. Capital asset prices: a theory of market equilibrium under conditions of risk. Journal of Finance, v. 19, n. 3, p. 425- 442, 1964.

STAMBAUGH, R. F. On the exclusion of assets from tests of the two-parameter model: a sensitivity analysis. Journal of Financial Economics, v. 10, n. 3, p. 237-268, 1982.

STATTMAN, D. Book values and stock returns. The Chicago MBA: A Journal of Selected Papers, v. 4, p. 25-45, spring, 1980.

STEIN, J. Rational capital budgeting in an irrational world. Journal of Business, v. 69, n. 4, p. 429-455, 1996.

TOBIN, J. Liquidity preference as behavior toward risk. Review of Economic Studies, v. 25, n. 2, p. 65-86, 1958.

VUOLTEENAHO, T. What drives firm level. Stock returns? Journal of Finance, v. 57, n. 1, p. 233-264, 2002.

\section{Artigo convidado. Aprovado em 16.03.2007.}

\section{Eugene F. Fama}

Professor de Finanças na Graduate Business School da Universidade de Chicago.

Interesses de pesquisa nas áreas investimentos, formação de preços em mercados de capitais e

finanças corporativas.

E-mail: eugene.fama@chigagoqsb.edu

Endereço: Avenue South Woodlawn, 5807, 60637, Chicago, IL, USA.

\section{Kenneth R. French}

Professor de Finanças na Tuck School of Business, da Universidade de Dartmouth

Interesses de pesquisa nas áreas de custo e estrutura de capital.

E-mail: kfrench@dartmouth.edu

Endereço: Tuck School of Business at Dartmouth. Tuck Hall, 100, 03755, Hanover, NH, USA. 